\title{
1. Evolution of geographic variation in thermal performance curves in the face of climate change and implications for biotic interactions

\author{
Nedim Tüzün and Robby Stoks
}

\begin{abstract}
6 We review the recent literature on geographic variation in insect 7 thermal performance curves (TPCs). Despite strong thermal 8 differences, there is often no change in TPCs across 9 geographic gradients. When shifts occur, these are mostly 10 vertical (indicating an overall shift in performance across 11 temperatures, that is, countergradient or cogradient variation) 12 and less horizontal (reflecting thermal adaptation). Based on 13 this, using a space-for-time substitution approach, we 14 generated likely evolutionary scenarios of TPC evolution to 15 simulate the outcome of biotic interactions under future 16 warming. We illustrate how taking evolution of the TPCs into 17 account may strongly impact the predicted outcome of biotic 18 interactions under climate warming. Importantly, both the type 19 and the magnitude of the TPC shift was identified to be crucial 20 to determine who will be winners and losers of biotic 21 interactions.
\end{abstract}

\section{Address}

22 Evolutionary Stress Ecology and Ecotoxicology, University of Leuven,
Deberiotstraat 32, 3000 Leuven, Belgium

Corresponding author: Stoks, Robby (robby.stoks@kuleuven.be)

Current Opinion in Insect Science 2018, 29:xx-yy

This review comes from a themed issue on Global change biology

Edited by Oswald Schmitz and Adam Rosenblatt

https://doi.org/10.1016/j.cois.2018.07.004

2214-5745/๑ 2018 Published by Elsevier Inc.

\section{Introduction}

Understanding how performance changes with temperature is crucial to assess the potential of populations to deal with current and future thermal regimes [1]. The relationship between a performance trait and temperature is known as the thermal performance curve (TPC). TPCs of insects typically have a rising part until the temperature where the best performance is reached (i.e. thermal optimum, or $\left.T_{\text {opt }}\right)$. Above this temperature, performance steeply decreases until reaching the critical thermal maximum $\left(\mathrm{CT}_{\max }\right)$, where performance becomes zero (Figure 1).
Populations across geographic gradients may experience strongly different thermal regimes. This holds both at the macrogeographic scale, for example along latitudinal and altitudinal gradients, and at the microgeographic scale, for example along urbanization gradients [2]. As a result, TPCs can strongly depend on the populations' geographic origin [3]. Studying the evolution of TPCs across geographic gradients is getting renewed interest to predict responses to climate change $[1,3]$. Using a space-fortime approach [4], the current TPC at a warmer site can indeed be used as a proxy to predict the TPC at a colder site under a given warming scenario.

Although it is increasingly accepted that the fate of populations to persist locally depends not only the ability to deal with warming perse, but also on the ability to deal with biotic interactions under warming [5], this has been much less studied. Very few studies indeed directly addressed how biotic interactions change along temperature-associated geographic gradients (e.g. [6,7]). Importantly, the outcome of biotic interactions such as consumer-resource interactions [8-10] and interspecific competition [11,12] at a given temperature can be predicted based on the TPCs of the interacting species. For example, comparing the TPCs for swimming speed of a predator and its prey, the predator attack speed was found to be lower than the prey escape speed below a certain temperature, which was suggested to be the reason of the mostly unsuccessful predator attacks below that temperature [10]. Therefore, geographic patterns of TPCs of interacting species may inform on geographic patterns of their interaction, and using a space-for-time approach also on the evolution of biotic interactions under future warming.

We here review recent work on TPCs across geographic gradients in insects and describe emerging patterns. Based on this review we then generate hypothetical scenarios of evolutionary changes in TPCs of two interacting species to infer possible patterns in the outcomes of their interactions in the face of future warming. We particularly highlight how evolution of the TPCs, often ignored in such studies, may affect the predictions of the outcome of the interaction between species in the face of climate change.

\section{General geographic patterns in TPCs}

Shifts in ectotherm TPCs along geographic gradients can show three, not mutually exclusive, patterns [13] that are visualized in Figure 1: 


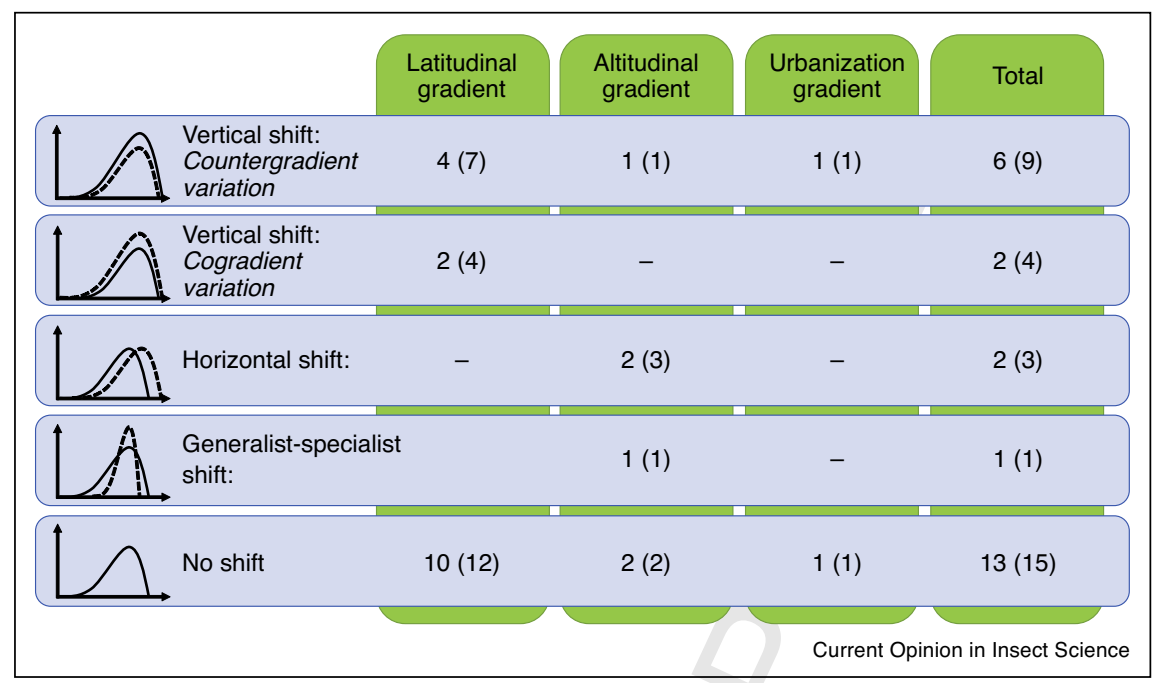

Schematic overview synthesizing the documented shifts in thermal performance curves (TPCs) along geographic gradients in insects. Numbers outside brackets give the total number of studies reporting a certain shift, numbers within brackets give the total numbers of traits showing a certain shift. Note that several studies reported different mode of TPC shifts for different traits (measured in the same study), resulting in an inflated 'total' number of studies (i.e. the total number of studies included in this review was 18 , instead of 24).

(i) A 'horizontal shift' occurs when warm/cold-adapted populations perform better at higher/lower temperatures. This pattern is often associated with local thermal adaptation, where the maximum performance is achieved at the temperature the population is adapted to $\left(T_{\mathrm{opt}}\right)$, and is driven by a trade-off between performance at higher and lower temperatures [14].

(ii) A 'vertical shift' occurs when populations outperform across temperatures. This may take two forms. The scenario where populations inhabiting colder regions outperform those from warmer regions is termed countergradient variation $(\mathrm{CnGV})$, as the genetic influence opposes the influence of the thermal environment. This shift, often documented for growth or development rate, is associated with stronger time constraints experienced in colder environments [15,16]. The opposite scenario where warm-adapted populations outperform cold-adapted populations along the thermal gradient, is called cogradient variation $(\mathrm{CoGV})$. Although the underlying drivers of this pattern are not clear, it is often detected for morphological traits [16].

(iii) A 'generalist-specialist shift' occurs when populations adapted to more stable thermal environments have a narrower thermal performance breadth (i.e. the temperature range where performance can occur) and higher maximum performance than populations adapted to more variable thermal environments $[17,18]$. This trade-off is suggested to be driven by structural constraints in the thermal flexibility and stability of enzymes [19].

Many studies have been testing geographic patterns in only the extreme values of the TPC: the minimum $\left(\mathrm{CT}_{\min }\right)$ and the maximum $\left(\mathrm{CT}_{\max }\right)$ temperature where performance becomes zero. Recent studies on insects confirm the general patterns that $\mathrm{CT}_{\min }$ is lower in high-latitude than in low-latitude populations, while $\mathrm{CT}_{\max }$ shows no or only a weak latitudinal pattern (reviewed in [20]; but see e.g. [21,22]). Along altitudinal gradients, the emerging pattern is that of a higher $\mathrm{CT}_{\max }$ at warmer, lower altitudes, and vice versa for $\mathrm{CT}_{\min }$ (e.g. $[23,24])$. It is important to note that the geographic patterns in the extremes of the TPC do not automatically inform about the type of shift in the entire TPC. For example, TPCs with a different CT $_{\max }$ may still have the same $T_{\mathrm{opt}}$ and vice versa.

\section{Geographic patterns in insect TPCs}

To identify geographic patterns in insect TPCs, we selected recent intraspecific studies with at least two geographically separated conspecific populations, that assessed performance at $\geq 3$ constant temperatures (the minimum requirement for constructing TPCs). We follow the definition of performance traits as biological rate processes with a time-dependent component [25]. We specifically focused on performance traits directly relevant for the outcome of biotic interactions in the short term (within a generation), thereby excluding cross-generational numerical effects. 
Specifically, we included individual growth rate, development time/rate, and consumption/feeding rate. We thereby make the reasonable assumption that higher values of these traits will make the organism better in dealing with a specific biotic interactor in the short term. For example, faster growing organisms in general do better in competitive interactions (e.g. [11]). Note that these performance traits do not necessarily translate into long-term fitness because of trade-offs [16]. We refer the reader to Table 1 for additional details of the selection criteria.

The selection criteria resulted in 18 insect studies (Table 1 ) dominated by two orders: lepidopterans (6 studies) and dipterans (4 studies). Development time and growth rate were by far the most frequently tested traits (17 studies). The majority of studies looked at macrogeographic gradients, mainly latitudinal (13 studies) and less frequently altitudinal gradients ( 2 studies), and only one study considered a microgeographic (urbanization) gradient. Two studies applied a mixed gradient, using populations that differed both in their latitudes and altitudes. These three gradients typically reflect temperature gradients with the higher temperatures at lower latitudes/altitudes, and at urban sites [2], causing plastic increases in the values of the studied performance traits.

Surprisingly, despite strong differences in thermal regimes, most studies revealed no change in TPCs across geographic gradients (Figure 1). The two reviews on geographic patterns in TPCs across all animals dealt either only with $\mathrm{CnGV}$ [15] or only with $\mathrm{CnGV}$ and CoGV patterns [16], hence cannot inform about the generality of the 'stasis' of TPCs. This lack of geographic signal may, however, partly reflect the often documented absence of latitudinal patterns in $\mathrm{CT}_{\max }$ [20]. The absence of a strong latitudinal pattern in $\mathrm{CT}_{\text {max }}$ has been recently explained by interference from range expansion events, where insect species undergoing large-scale range expansions seem to show a latitudinal invariance of $\mathrm{CT}_{\max }$ [26]. Other explanations for a lack of TPC shifts involve perfect compensation under $\mathrm{CnGV}$ resulting in no clinical trait variation (for body size TPCs: [16,27-29]), and too short time since the divergence of the study populations [30].

Among the insect studies where a geographic signal was detected, the most common pattern was a vertical shift in TPCs, whereas horizontal shifts were less prevalent. This is often suggested to be due to constraints on the physiological underpinnings of performance: horizontal shifts of TPCs require radical changes to the structural and physiological characteristics of enzymes, which is considered as an evolutionarily conserved system [13,31]. Vertical shifts, on the other hand, are primarily driven by upregulation or down-regulation of enzymes, which is a more evolutionarily labile process [32]. Among the two vertical shift models, $\mathrm{CnGV}$ patterns were more common than CoGV patterns, in agreement with the findings of the review by Conover et al. [16] including also non-insect studies where $\mathrm{CnGV}$ was overwhelmingly dominant over CoGV (also for insects, 13 vs 2 studies: [16]). Notably, only one insect study reported a correlated change in TPC breadth and maximal performance along a geographic gradient, reflecting a generalist-specialist shift [33]. Yet caution is warranted, as reliable detection of this mode of TPC shift requires specific experimental and statistical designs, such as a temperature gradient spanning the entire thermal spectrum of the study organism, and explicitly measuring the trade-off between $T_{\mathrm{opt}}$ and thermal performance breadth.

\section{Predicting interaction outcomes under future warming based on evolving TPCs}

Differences in TPCs between two interacting species have been successfully used to predict the outcome of their pairwise interaction in the short term (e.g. [10]). Based on this, we hypothesize that patterns in TPCs along geographic gradients can be useful tools to predict how species interactions will change along these gradients. Moreover, we can use the TPC of a given species at the warmer site of a gradient to infer how the TPC at the colder site will evolve under future warming (i.e. spacefor-time: [4]).

We simulated six scenarios how an evolutionary shift in the TPC of a species A (matching a current geographic TPC pattern) may shape the outcome of the interaction in the short term with a species B (Figure 2). Because no geographic shift in TPC was the most common geographic pattern detected in our literature review (Figure 1), we assume that the TPC of species B does not evolve. We based the evolution of the TPC of species A on the three most observed geographic shifts in insect TPCs (CnGV, CoGV, and horizontal shift); for each shift type we considered the effect of a moderate and a strong shift. In each scenario the current temperature at which both species interact is $t 1$ and the future temperature under climate change is $\mathrm{t} 2$. In the current scenario (at $t 1$ ) species A is superior compared to species B. Without evolution of the TPC, species A will, however, become inferior compared to species B under future warming at that site (at t2).

A first pair of evolutionary scenarios assumes a downward vertical shift (matching CnGV) of the TPC of species A. This will result in lower performance of species A under future warming, hence shifts the outcome of the interaction in favour of species B (Figure 2a). Note that in this case, evolution of the TPC of species A will be maladaptive in terms of the outcome of the interaction with species B. Increasing the magnitude of the downward vertical shift will further decrease the performance of species A (Figure 1d). On the other hand, when species A evolves an upward vertical shift (matching CoGV), 
Table 1

Recent (last 5 years) studies testing for geographic patterns in insect thermal performance curves (TPCs). To infer the type of TPC shifts, we primarily relied on the authors' interpretation of the results. When not explicitly mentioned, we describe the pattern based on statistical results and visual inspection of the TPCs. We interpreted a significant main effect of geographic origin (e.g. latitude) as a signal of a vertical shift in TPCs. Depending on the alignment with the geographic gradient, the vertical shift was described as either countergradient variation (CnGV) or cogradient variation (CoGV). In case of a significant geographic origin $\times$ rearing temperature interaction, we checked whether the $T_{\text {opt }}$ differed along the gradient, which would indicate a horizontal shift in TPCs. Finally, a negative correlation between $T_{\text {opt }}$ and thermal performance breadth was interpreted as a shift in the TPC breadth (generalist-specialist shift). We excluded traits that did not show temperature dependency. When TPCs crossed, we considered this as an irregular pattern. When traits reacted to temperature but the TPCs did not shift along the geographic gradient, we indicated this as 'no shift'. We only included common-garden studies where animals from the different populations were reared from the egg stage, as TPCs from field-collected individuals cannot inform on the genetic basis of any potential shift

\begin{tabular}{|c|c|c|c|c|c|c|}
\hline Group & Species & Trait & $\begin{array}{c}\text { Gradient } \\
\text { (no. of populations) }\end{array}$ & $\begin{array}{l}\text { Geographic } \\
\text { pattern }\end{array}$ & $\begin{array}{c}\text { No. of } \\
\text { temperatures }\end{array}$ & Reference \\
\hline Collembola & Folsomia quadrioculata & Development time & Latitude (10) & No & 3 & [44] \\
\hline \multirow[t]{2}{*}{ Collembola } & Folsomia quadrioculata & Growth rate (juvenile) & Latitude (5) & No & 4 & [45] \\
\hline & & $\begin{array}{l}\text { Development time } \\
\text { (age at first } \\
\text { reproduction) }\end{array}$ & & No & & \\
\hline Diptera & Drosophila subobscura & $\begin{array}{l}\text { Development time } \\
\text { (age at first } \\
\text { reproduction) }\end{array}$ & Latitude (3) & No & 3 & [46] \\
\hline Diptera & Culex pipiens & Development rate & Latitude/Altitude (4) & No & 6 & {$\left[47^{\circ}\right]$} \\
\hline Diptera & Sepsis punctum & Development rate & Latitude (3) & $\mathrm{CnGV}^{\mathrm{a}}$ & 5 & [31] \\
\hline \multirow[t]{2}{*}{ Diptera } & Sepsis thoracica & Development time & Latitude (45) & CnGV & 3 & [29] \\
\hline & & Growth rate & & CnGV & & \\
\hline Lepidoptera & Ematurga atomaria & $\begin{array}{l}\text { Development time } \\
\text { Growth rate }\end{array}$ & Latitude/Altitude (4) & $\begin{array}{l}\text { CnGV } \\
\text { No }\end{array}$ & 3 & [48] \\
\hline Lepidoptera & Bicyclus safitza & $\begin{array}{l}\text { Development time } \\
\text { Growth rate }\end{array}$ & Latitude (2) & $\begin{array}{l}\text { Irregular } \\
\text { Irregular }\end{array}$ & 4 & [49] (supplementary) \\
\hline \multirow[t]{2}{*}{ Lepidoptera } & Ostrinia furnacalis & Development time & Latitude (4) & No & 7 & [50] \\
\hline & & Growth rate & & No & & \\
\hline \multirow[t]{2}{*}{ Lepidoptera } & Heteronympha merope & Development time & Latitude (5) & CoGV & 3 & [51] \\
\hline & & Growth rate & & CoGV & & \\
\hline Lepidoptera & Loxostege sticticalis & Development time & Latitude (3) & No & 4 & [52] \\
\hline Lepidoptera & Colias eurytheme & Feeding rate & Altitude (2) & $\begin{array}{l}\text { Generalist-specialist } \\
\text { and horizontal }\end{array}$ & $5-6$ & [33] \\
\hline Lepidoptera & Colias eriphyle & Feeding rate & Altitude (2) & Horizontal & 10 & [33] \\
\hline Coleoptera & Lilioceris cheni & Development time & Latitude $^{\mathrm{b}}(2)$ & No & 4 & [53] \\
\hline \multirow[t]{3}{*}{ Coleoptera } & Colaphellus bowringi & $\begin{array}{l}\text { Development time } \\
\text { (larval) }\end{array}$ & Latitude (6) & CoGV & 6 & {$\left[54^{\circ}\right]$} \\
\hline & & $\begin{array}{l}\text { Development time } \\
\text { (pupal) }\end{array}$ & & No & & \\
\hline & & Growth rate & & CoGV & & \\
\hline \multirow[t]{3}{*}{ Orthoptera } & Melanoplus femurrubrum & Development time & Latitude (4) & CnGV & 3 & {$\left[55^{\bullet \bullet}\right]$} \\
\hline & & Growth rate & & CnGV & & \\
\hline & & Consumption rate & & CnGV & & \\
\hline Orthoptera & Melanoplus sanguinipes & Development time & Altitude (3) & Horizontal & 3 & [56] \\
\hline Hymenoptera & Pachycrepoideus vindemiae & Development rate & Latitude $^{c}$ & No & 8 & [57] \\
\hline \multirow[t]{2}{*}{ Odonata } & Coenagrion puella & Growth rate (larval) & Urbanisation (6) & CnGV & 5 & {$\left[58^{\circ}\right]$} \\
\hline & & $\begin{array}{l}\text { Development time } \\
\text { (egg) }\end{array}$ & & No & & \\
\hline
\end{tabular}

a The CnGV pattern was between central and southern populations, but not between central and northern population.

${ }^{b}$ Authors defined the two populations as biotypes, and do not mention a latitudinal gradient.

${ }^{c}$ Authors did not explicitly define the gradient as latitudinal, but as microclimatic.

species A will improve its performance at $\mathrm{t} 2$ compared to a situation where its TPC does not evolve Figure 2b), and may even evolve a higher performance than species B if the magnitude of shifting is strong enough (Figure 2e). A final pair of evolutionary scenarios assumes a horizontal shift of the TPC of species A. Under a moderate horizontal shift, species A will improve its performance at t2 compared to a situation where its TPC does not evolve (Figure 2c). If the magnitude of horizontal shifting is strong enough, species A may even evolve the same 266 performance as species B (Figure 2f).

\section{Current studies using TPCs to predict biotic interactions under future warming}

Empirical studies that incorporated spatial patterns in (and associated evolution of) TPCs of interacting species to predict the outcome of their interaction under warming are extremely rare (but see [11] for a study with tunicates 

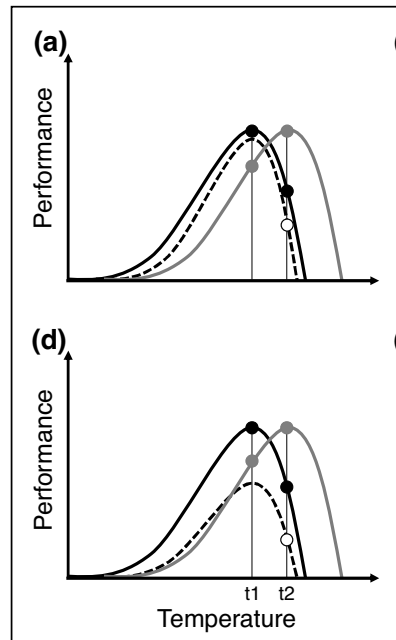

(b)

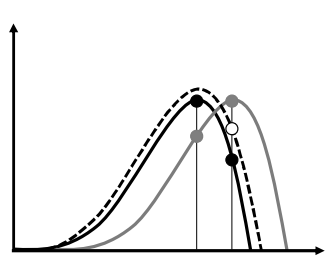

(e)

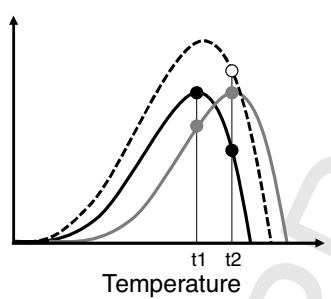

(c)

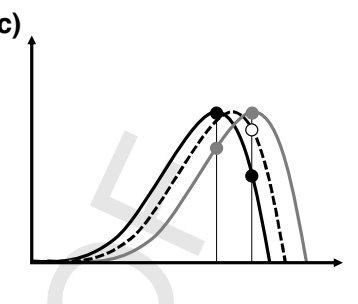

(f)

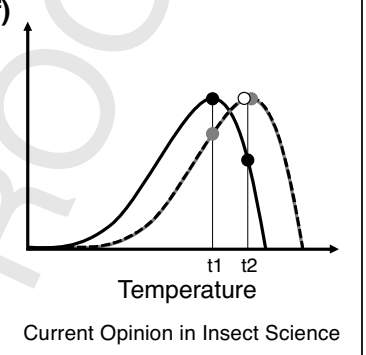

Conceptual diagrams of some hypothetical combinations of thermal performance curves (TPCs) of two interacting species, illustrating how evolutionary shifts in the TPC of one species may shape the outcome of the interaction between the two species. Species A (black) reaches its maximum performance at temperature $t 1$, while species $B$ reaches its maximum performance at $t 2$. Dots located on the TPCs represent the performance of species A (black or white) and species B (grey) at the given temperature (t1 or t2). The two species outperform each other when located in their optimal thermal environment; that is, the black dot is higher than the grey dot at $t 1$, and vice versa at $t 2$. The dashed black lines represent the new TPC of species A after evolution, assuming evolution matches a common geographic scenario of TPC shifting (based on Figure 1). Six evolutionary scenarios are shown that differ in the direction and magnitude of the evolutionary shift of the TPC of species A. The six scenarios match moderate (a) and strong (d) countergradient variation, moderate (b) and strong (e) cogradient variation, and moderate (c) and strong (f) horizontal shifting of the TPC. Note that these simplified scenarios assume identical TPC shapes for the two species, and no evolution of the TPC of species B.

and bryozoans). Instead, fragmentary pieces of information exist. The many studies on geographic variation in TPCs (Figure 1) did not explicitly consider biotic interactions. Further, it has been widely documented that trophic interactions can show strong spatial patterns (for insects: [34-36]). Yet, these patterns are often attributed to density-related changes, and have not been linked to geographic differentiation in (thermal) performances. Other studies predicted species interactions in the face of future climates based on current TPCs (see below), yet ignored evolution and did not make a link to geographic patterns in TPCs. One notable exception is the conceptual framework put forward by Sternberg and Thomas $\left[37^{\circ \bullet}\right]$, where they simulated changes in TPCs (relevant for long-term interactions) to predict how local adaptation may alter responses of vector-borne diseases to climate warming.

The biotic interaction types best studied in the context of future warming that integrated TPCs are those between hosts and their parasites/parasitoids $\left[38^{\bullet \bullet}, 39,40,41^{\bullet \bullet}\right]$, as well as host-symbiont interactions [42]. Although these interactions are driven by more factors than the here studied performance traits, and these studies often measure traits relevant for long-term interactions (e.g. population growth rate), applying the insights obtained above is still relevant. A recent review comparing key TPC parameters $\left(T_{\mathrm{opt}}, \mathrm{CT}_{\min }, \mathrm{CT}_{\max }\right)$ for development rate between insect hosts and their parasitoids reported lower $T_{\text {opt }}$ in parasitoids than their hosts, suggesting parasitoids to be more vulnerable to increasing temperatures relative to their hosts [40]. This was further supported by a followup study where the effects of climate change on hostparasitoid interactions were modelled using the diamondback moth Plutella xylostella and its parasitoid Diadegma semiclausum [40]. Similar findings were derived from a modelling study using TPCs (of reproduction and lifespan) of a reef-dwelling crab and its rhizocephalan parasite, predicting reduced parasitism with future warming $\left[43^{\circ}\right]$. Although providing extremely valuable insight, both modelling studies ignored the potential of evolution changing the TPCs under warming. As indicated by the review summarized in Figure 1, this matches the 'no shift' scenario that indeed is common. Yet, in many cases TPCs have been shown to evolve along spatial gradients. The distinct, sometimes opposing hypothetical outcomes (demonstrated in Figure 2) highlight the importance of considering evolution of TPCs when predicting the dynamics of biotic interactions under climate change. This highlights that TPC evolution has the potential to strongly modify and even reverse the outcome of the interactions between hosts and their parasite/parasitoids under future warming compared to predictions by the models assuming no evolution. 


\section{Conclusions and future directions}

Our review on recent insect studies identified that in many cases TPCs do not show geographic differentiation along strong thermal gradients, suggesting TPCs of these species will not evolve in situ under warming. Yet, in many other cases, a geographic signal was detected, mainly taking the forms of $\mathrm{CnGV}$, and to a lesser extent CoGV and horizontal shifts. Hypothetical scenarios showed that in such cases taking evolution of the TPC into account may have a very strong impact on the predicted outcome of biotic interactions under warming. Moreover, besides the type also the magnitude of the TPC shift was identified to be crucial to determine who will be winners and losers. Unfortunately, current case studies that predicted effects of future warming based on TPCs did not consider evolution. Our results indicate that integrating information on geographic variation in TPCs when modelling the outcome of interactions would be an important step in increasing realism when predicting how biotic interactions will change under future climate change.

\section{Conflict of interest statement}

Nothing declared.

\section{Acknowledgements}

This work was supported by Belspo project Speedy, the KU Leuven Centre of Excellence program PF/2010/07, FWO research grant G.0524.17 and FWO scientific network EVE-net. Comments by Adam Rosenblatt and an anonymous reviewer greatly improved this paper.

\section{References and recommended reading}

Papers of particular interest, published within the period of review, have been highlighted as

- of special interest

•. of outstanding interest

1. Sinclair BJ, Marshall KE, Sewell MA, Levesque DL, Willett CS, Slotsbo S, Dong Y, Harley CDG, Marshall DJ, Helmuth BS et al.: Can we predict ectotherm responses to climate change using thermal performance curves and body temperatures? Ecol Lett 2016, 19:1372-1385.

2. Brans KI, Engelen JMT, Souffreau C, De Meester L: Urban hottubs: local urbanization has profound effects on average and extreme temperatures in ponds. Landsc Urban Plan 2018, 176:22-29.

3. Sinclair BJ, Williams CM, Terblanche JS: Variation in thermal performance among insect populations. Physiol Biochem Zool 2012, 85:594-606.

4. Stoks R, Geerts AN, De Meester L: Evolutionary and plastic responses of freshwater invertebrates to climate change: realized patterns and future potential. Evol Appl 2014, 7:42-55.

5. Urban MC, Bocedi G, Hendry AP, Mihoub J-B, Pe'er G, Singer A, Bridle JR, Crozier LG, De Meester L, Godsoe W et al:: Improving the forecast for biodiversity under climate change. Science 2016, 353:aad8466.

6. De Block M, Pauwels K, Van Den Broeck M, De Meester L, Stoks R: Local genetic adaptation generates latitude-specific effects of warming on predator-prey interactions. Glob Chang Biol 2013, 19:689-696.

7. Tran TT, Janssens L, Dinh KV, Op de Beeck L, Stoks R: Evolution determines how global warming and pesticide exposure will shape predator-prey interactions with vector mosquitoes. Evol Appl 2016, 9:818-830.
8. Dell Al, Pawar S, Savage VM: Temperature dependence of trophic interactions are driven by asymmetry of species responses and foraging strategy. J Anim Ecol 2014, 83:70-84.

9. Amarasekare $P$ : Effects of temperature on consumer-resource interactions. J Anim Ecol 2015, 84:665-679.

10. Öhlund G, Hedstrom P, Norman S, Hein CL, Englund G: Temperature dependence of predation depends on the relative performance of predators and prey. Proc $R$ Soc $B$ Biol Sci 2015, 282:20142254.

11. Lord J, Whitlatch R: Predicting competitive shifts and responses to climate change based on latitudinal distributions of species assemblages. Ecology 2015, 96:1264-1274.

12. Fey SB, Cottingham KL: Thermal sensitivity predicts the establishment success of nonnative species in a mesocosm warming experiment. Ecology 2012, 93:2313-2320.

13. Angilletta MJ: Thermal Adaptation: $A$ Theoretical and Empirical Synthesis. Oxford University Press; 2009.

14. Kingsolver JG: The well-temperatured biologist. Am Nat 2009 , 174:755-768.

15. Conover DO, Schultz ET: Phenotypic similarity and the evolutionary significance of countergradient variation. Trends Ecol Evol 1995, 10:248-252.

16. Conover DO, Duffy TA, Hice LA: The covariance between genetic and environmental influences across ecological gradients: reassessing the evolutionary significance of countergradient and cogradient variation. Ann N Y Acad Sci 2009, 1168:100-129.

17. Deutsch CA, Tewksbury JJ, Huey RB, Sheldon KS, Ghalambor CK Haak DC, Martin PR: Impacts of climate warming on terrestrial ectotherms across latitude. Proc Natl Acad Sci USA 2008, 105:6668-6672.

18. Sunday JM, Bates AE, Dulvy NK: Global analysis of thermal tolerance and latitude in ectotherms. Proc R Soc B Biol Sci 2011, 278:1823-1830.

19. Huey RB, Kingsolver JG: Evolution of thermal sensitivity of ectotherm performance. Trends Ecol Evol 1989, 4:131-135.

20. Addo-Bediako A, Chown SL, Gaston KJ: Thermal tolerance, climatic variability and latitude. Proc $R$ Soc B Biol Sci 2000 267:739-745.

21. Barton BT: Local adaptation to temperature conserves topdown control in a grassland food web. Proc $R$ Soc B Biol Sci 2011, 278:3102-3107.

22. Rezende EL, Castañeda LE, Santos M: Tolerance landscapes in thermal ecology. Funct Ecol 2014, 28:799-809.

23. García-Robledo C, Kuprewicz EK, Staines CL, Erwin TL, Kress WJ Limited tolerance by insects to high temperatures across tropical elevational gradients and the implications of global warming for extinction. Proc Natl Acad Sci USA 2016, 113:680685.

24. Oyen KJ, Giri S, Dillon ME: Altitudinal variation in bumble bee (Bombus) critical thermal limits. J Therm Biol 2016, 59:52-57.

25. Schulte PM, Healy TM, Fangue NA: Thermal performance curves, phenotypic plasticity, and the time scales of temperature exposure. Integr Comp Biol 2011, 51:691-702.

26. Lancaster LT: Widespread range expansions shape latitudinal variation in insect thermal limits. Nat Clim Chang 2016, 6:618621.

27. Laugen AT, Laurila A, Räsänen K, Merilä J: Latitudinal countergradient variation in the common frog (Rana temporaria) development rates - evidence for local adaptation. J Evol Biol 2003, 16:996-1005.

28. Blanckenhorn WU, Demont M: Bergmann and converse Bergmann latitudinal clines in arthropods: two ends of a continuum? Integr Comp Biol 2004, 44:413-424.

29. Blanckenhorn WU, Bauerfeind SS, Berger D, Davidowitz G, Fox CW, Guillaume F, Nakamura S, Nishimura K, Sasaki H, 
Stillwell RC et al.: Life history traits, but not body size, vary systematically along latitudinal gradients on three continents in the widespread yellow dung fly. Ecography $2018 \mathrm{http}: / / \mathrm{dx} . \mathrm{doi}$ org/10.1111/ecog.03752.

30. Gibert P, Hill M, Pascual M, Plantamp C, Terblanche JS, Yassin A Sgrò CM: Drosophila as models to understand the adaptive process during invasion. Biol Invasions 2016, 18:1089-1103.

31. Berger D, Postma E, Blanckenhorn WU, Walters RJ: Quantitative genetic divergence and standing genetic (co)variance in thermal reaction norms along latitude. Evolution 2013, 67:23852399.

32. Angilletta MJ, Wilson RS, Navas CA, James RS: Tradeoffs and the evolution of thermal reaction norms. Trends Ecol Evol 2003 18:234-240.

33. Higgins JK, MacLean HJ, Buckley LB, Kingsolver JG: Geographic differences and microevolutionary changes in thermal sensitivity of butterfly larvae in response to climate. Funct Ecol 2014, 28:982-989.

34. Roslin T, Andrew NR, Asmus A, Barrio IC, Basset Y: Higher predation risk for insect prey at low latitudes and elevations. Science 2017, 356:742-744.

35. Turrini $T$, Sanders $D$, Knop E: Effects of urbanization on direct and indirect interactions in a tri-trophic system. Ecol Appl 2016, 26:664-675.

36. Baskett CA, Schemske DW: Latitudinal patterns of herbivore pressure in a temperate herb support the biotic interactions hypothesis. Ecol Lett 2018, 21:578-587.

37. Sternberg ED, Thomas MB: Local adaptation to temperature - $\quad$ and the implications for vector-borne diseases. Trends Parasitol 2014, 30:115-122.

This important conceptual paper is the first to apply simulated changes in TPCs to predict how local adaptation may alter responses of vector borne diseases to climate warming.

38. Furlong MJ, Zalucki MP: Climate change and biological control: - the consequences of increasing temperatures on hostparasitoid interactions. Curr Opin Insect Sci 2017, 20:39-44. An important review on TPCs for development rates of insect parasitoids and their insect hosts. The work includes a case study where the effects of climate change on a host-parasitoid interaction are modelled.

39. Thomas MB, Blanford S: Thermal biology in insect-parasite interactions. Trends Ecol Evol 2003, 18:344-350.

40. Hance $T$, van Baaren J, Vernon P, Boivin G: Impact of extreme temperatures on parasitoids in a climate change perspective. Annu Rev Entomol 2007, 52:107-126.

41. Cohen JM, Venesky MD, Sauer EL, Civitello DJ, McMahon TA

-. Roznik EA, Rohr JR: The thermal mismatch hypothesis explains host susceptibility to an emerging infectious disease. Ecol Lett 2017, 20:184-193.

This outstanding case study demonstrates the importance of detecting 'gaps' in thermal performances between two interacting species, in this case a host-parasite system, when predicting of the interaction outcome (e.g. disease outbreaks) under climate change.

42. Corbin C, Heyworth ER, Ferrari J, Hurst GDD: Heritable symbionts in a world of varying temperature. Heredity 2017, 118:10-20.

43. A-LM Gehman, Hall RJ, Byers JE: Host and parasite thermal -. ecology jointly determine the effect of climate warming on epidemic dynamics. Proc Natl Acad Sci Sci USA 2018, 115:201705067.

An outstanding modelling study highlighting the importance of considering TPCs of both the hosts and parasites to accurately predict effects of warming on infection dynamics. The study uses empirically derived TPCs together with field data on seasonal host abundance and parasite prevalence.

44. Sengupta S, Ergon T, Leinaas HP: Genotypic differences in embryonic life history traits of Folsomia quadrioculata (Collembola: Isotomidae) across a wide geographical range. Ecol Entomol 2016, 41:72-84.
45. Sengupta S, Ergon T, Leinaas HP: Thermal plasticity in postembryonic life history traits of a widely distributed Collembola: effects of macroclimate and microhabitat on genotypic differences. Ecol Evol 2017, 7:8100-8112.

46. Fragata I, Lopes-Cunha M, Bárbaro M, Kellen B, Lima M, Faria GS, Seabra SG, Santos M, Simões P, Matos M: Keeping your options open: maintenance of thermal plasticity during adaptation to a stable environment. Evolution 2016, 70:195-206.

47. Ruybal JE, Kramer LD, Kilpatrick AM: Geographic variation in the - $\quad$ response of Culex pipiens life history traits to temperature. Parasit Vectors 2016, 9:116.

This empirical study, using mosquito populations that differ in their altitude and latitudes, stands out from similar studies with the inclusion of TPCs of biting rates.

48. Meister H, Hämäläinen HR, Valdma D, Martverk M, Tammaru T: How to become larger: ontogenetic basis of amongpopulation size differences in a moth. Entomol Exp Appl 2018 166:4-16.

49. Nokelainen O, Van Bergen E, Ripley BS, Brakefield PM: Adaptation of a tropical butterfly to a temperate climate. Biol J Linn Soc 2018, 123:279-289.

50. Xiao L, He HM, Huang LL, Geng T, Fu S, Xue F, Sen: Variation of life-history traits of the Asian corn borer, Ostrinia furnacalis in relation to temperature and geographical latitude. Ecol Evol 2016, 6:5129-5143.

51. Barton M, Sunnucks P, Norgate M, Murray N, Kearney M: Cogradient variation in growth rate and development time of a broadly distributed butterfly. PLoS One 2014, 9:e95258.

52. Kutcherov D, Saulich A, Lopatina E, Ryzhkova M: Stable and variable life-history responses to temperature and photoperiod in the beet webworm, Loxostege sticticalis. Entomol Exp Appl 2015, 154:228-241.

53. Manrique V, Lake EC, Smith MC, Diaz R, Franko C, Pratt PD, Rayamajhi MB, Overholt WA: Comparative evaluation of development and reproductive capacity of two biotypes of Lilioceris cheni (Coleoptera: Chrysomelidae), biological control agents of air potato (Dioscorea bulbifera) in Florida. Ann Entomol Soc Am 2017, 110:310-316.

54. Tang $\mathrm{J}, \mathrm{He} \mathrm{H}$, Chen $\mathrm{C}$, Fu S, Xue F: Latitudinal cogradient - variation of development time and growth rate and a negative latitudinal body weight cline in a widely distributed cabbage beetle. PLoS One 2017, 12:e0181030.

An empirical TPC study with a cabbage beetle originating along latitudinal gradient, revealing the association between a negative latitudinal body mass cline and latitudinal cogradient variation in development time and growth rates.

55. Parsons SMA, Joern A: Life history traits associated with body -. size covary along a latitudinal gradient in a generalist grasshopper. Oecologia 2014, 174:379-391.

This empirical study assessed TPCs of grasshopper populations along a 2000-km latitudinal gradient. Importantly, next to growth rate and devel opment time, the authors also built TPCs of the often ignored physiological traits such as metabolic rate and consumption, which can drive observed latitudinal clines in body size.

56. Buckley LB, Nufio CR, Kirk EM, Kingsolver JG: Elevational differences in developmental plasticity determine phenological responses of grasshoppers to recent climate warming. Proc $R$ Soc B Biol Sci 2015, 282:20150441.

57. Wang X-G, Serrato MA, Son Y, Walton VM, Hogg BN, Daane KM Thermal performance of two indigenous pupal parasitoids attacking the invasive Drosophila suzukii (Diptera: Drosophilidae). Environ Entomol 2018 http://dx.doi.org/10.1093/ ee/nvy053.

58. Tüzün N, Op de Beeck L, Brans KI, Janssens L, Stoks R:

- Microgeographic differentiation in thermal performance curves between rural and urban populations of an aquatic insect. Evol Appl 2017, 10:1067-1075.

The only insect TPC study conducted at a microgeographic scale, documenting countergradient variation driven by urbanization. 